\title{
Effect of $\gamma$-Irradiation on Thermal Properties of MWCNTs Reinforced HDPE
}

\author{
Nitturi Naresh Kumar, P. S. Rama Sreekanth and S. Kanagaraj
}

\begin{abstract}
Crosslinking by gamma irradiation is a key technique employed in industrial and medical application of polymers to improve their mechanical and thermal properties. The objective of the present work is to investigate the effect of gamma irradiation on thermal properties of high density polyethylene (HDPE) reinforced with multiwalled carbon nanotubes (MWCNTs). The chemically treated MWCNTs were coated on HDPE pellets using nanofluid based deposition technique under continuous stirring, which were processed in an injection moulding machine to obtain nanocomposites having $0.25,0.50,0.75$ and $1.0 \mathrm{wt} \%$ of MWCNTs. The nanocomposites thus obtained were exposed to $\gamma$-irradiation in the presence of air at 50 and $100 \mathrm{kGy}$ doses. Thermal characterization of nanocomposites was studied using DSC, TGA and TMA techniques. The results obtained from the DSC studies revealed that the melting point of nanocomposites was not significantly influenced by the presence of MWCNTs, while $\gamma$-irradiation resulted a marginal change. The crystallinity of the nanocomposites was increased from $37.4 \%$ for unirradiated HDPE to $55.8 \%$ for $1.0 \mathrm{wt} \%$ and $100 \mathrm{kGy}$ irradiated sample, which corresponds to $49 \%$ enhancement. The onset temperature of degradation of nanocomposites was found to be influenced by both MWCNTs and irradiation dosage, which was increased by $16{ }^{\circ} \mathrm{C}$ for $100 \mathrm{kGy}$ irradiated $1 \mathrm{wt} \%$ nanocomposite compared to unirradiated pure polymer. It is also found that the dimensional stability of the nanocomposites was increased by the reinforcement of MWCNTs. It is concluded from the above studies that thermal properties of nanocomposites are significantly influenced by the irradiation process and the concentration of MWCNTs.
\end{abstract}

N. N. Kumar · P. S. Rama Sreekanth · S. Kanagaraj ( $ه)$

Department of Mechanical Engineering, Indian Institute of Technology Guwahati,

Guwahati, Assam 781039, India

e-mail: kanagaraj@iitg.ernet.in 
Keywords Gamma irradiation - MWCNTs • Crystallinity • Thermo-mechanical analysis

\section{Introduction}

High density polyethylene (HDPE) is a semicrystalline polymer and ideal for industrial and medical applications because of its light weight, ease of processing, resistance to chemical corrosion, toughness and low cost of production. Due to biocompatible and bioinert nature of HDPE, it is explored in bone plates, bone screws, facial implants, orbital implants, artificial limbs and low load-bearing devices. Even though a wide variety of materials is being used as a cervical disc, HDPE has significant relevance due to its characteristics in addition to high cushioning effect [1].

During the last decade, researchers have attempted to improve physical, mechanical and thermal properties of HDPE for various applications. Different types of reinforcements such as carbon nanotubes (CNTs), graphite, hydroxyapatite (HA), calcium carbonate $\left(\mathrm{CaCO}_{3}\right)$, wollastonite etc., have been used in order to improve the properties of HDPE [2-6]. Among the above mentioned reinforcements, CNTs are an ideal filler material due to their high Young's modulus combined with low density, good electrical and thermal conductivity to prepare polymer nanocomposites [7]. Fouad et al. [8] prepared MWCNTs (up to $8 \%$ ) with HDPE via twin-screw extruder and injection moulding. It was observed that MWCNTs had no influence on melting temperature of nanocomposites; however, the crystallinity of the test material was reported to increase. Trujillo et al. [9] studied thermal properties of $\mathrm{HDPE} / \mathrm{MWCNTs} / \mathrm{Al}_{2} \mathrm{O}_{3}$ nanocomposites and reported that the onset temperature of degradation and melting temperature of nanocomposites were found to be decreased with an increase of concentration of reinforcement. Chrissafis et al. [10] studied fumed silica nanoparticles $\left(\mathrm{SiO}_{2}\right)$ HDPE composites filled with up to $5 \mathrm{wt} \%$ of reinforcement. Though the heat of fusion and the degree of crystallinity of composites were found to be decreased with filler content, no significant improvement on melting temperature was observed. Sahebian et al. [11] reported that the filler content had no influence on melting temperature of $\mathrm{HDPE} / \mathrm{CaCO}_{3}$ composites but thermal expansion of them was restricted by the reinforcement of $\mathrm{CaCO}_{3}$. Kodjie et al. [12] prepared HPDE/ SWCNTs $(0.1,0.25,0.50$ and $1.0 \mathrm{wt} \%)$ nanocomposites by solution blending technique and studied their characteristics. It showed that melting temperature of the nanocomposites was increased by $2{ }^{\circ} \mathrm{C}$ but the crystallinity was reduced by $4 \%$ at $1.0 \mathrm{wt} \%$ of SWCNTs loading. In addition to that thermal stability of HDPE was also enhanced by $115^{\circ} \mathrm{C}$.

Gamma irradiation is widely used in industries for different purposes including medical sterilization and crosslinking of the polymers, which can be accomplished by chemically or irradiation [13]. As mechanical, thermal and thermo-physical properties of polymers are expected to be influenced by the crosslinking process [14], 
it is required to study the changes in the properties of polymeric material induced by the irradiation. The effects of gamma irradiation up to 1,000 kGy on HDPE have been studied by Puig et al. [15]. It was reported that the melting temperature of polymer was increased at low irradiation dose up to $150 \mathrm{kGy}$ thereafter it was reduced gradually. Cataño et al. [16] reported that the onset temperature of degradation and melting temperature of $\mathrm{HDPE} / \mathrm{CaCO}_{3}$ composites remained constant at different concentration of reinforcement and irradiation dose, however, the activation energy and degree of crystallinity was increased with filler content but not varied significantly with irradiation dose. Carmen et al. [17] studied the effect of gamma irradiation on HDPE/HA composites. It was noted that melting temperature of the composites was remained constant irrespective of concentration of the reinforcement. It was also observed that the crystallinity of composites was increased with filler concentration but it was decreased by $17 \%$ when the test materials were exposed to $\gamma$-irradiation.

Though mechanical and thermal properties of MWCNTs reinforced HDPE have been reported, the influence of irradiation effect on thermal properties of the nanocomposites with varying concentration of MWCNTs have been not found in detail in the literature. Hence, the proposed study is focused on thermal characterization of irradiated HDPE/MWCNTs nanocomposites.

\section{Materials and Methods}

\subsection{Materials}

The nanocomposites with different concentrations, such as $0.25,0.50,0.75$, $1.00 \mathrm{wt} \%$ of MWCNTs were received in the form of hemispherical cup representing a acetabular cup from Prof. Jose Simoes, University of Aveiro, Portugal. The materials used and processing techniques followed to prepare the nanocomposites were described in detail by Kanagaraj et al. [18].

\subsection{Methods}

The test materials were gamma irradiated with a ${ }^{60}$ cobalt source at room temperature in the presence of air at a dosage rate of $2.5 \mathrm{kGy} / \mathrm{hr}$ up to 50 and $100 \mathrm{kGy}$ dosage level at M/s Microtrol sterilization Pvt. Ltd, Bangalore. Thermal analysis of the test sample was performed using a NETZSCH simultaneous thermal analyser (DSC \& TGA, model STA 449F3). Samples $(5.0 \pm 0.1 \mathrm{mg})$ were heated in Argon atmosphere from room temperature to $550{ }^{\circ} \mathrm{C}$. The thermo-mechanical analysis (TMA) of the nanocomposites was carried out using a Thermo-mechanical analyzer (TMA), Model Exstra 6000 (TMA/SS6000, Seiko Instruments Inc. Japan). The test sample was 
cylindrical in shape with $8 \mathrm{~mm}$ diameter and $2 \mathrm{~mm}$ thickness and it was heated from 35 to $85^{\circ} \mathrm{C}$ in air under a static load of $10 \mathrm{mN}$ applied on the sample through the expansion probe. All the experiments were performed at a heating rate of $10{ }^{\circ} \mathrm{C} / \mathrm{min}$. As recommended by ASTM F2625-10 standard.

\section{Results and Discussion}

\subsection{Differential Scanning Calorimetry Analysis}

Melting endotherms of unirradiated and irradiated nanocomposites were analyzed by Differential Scanning Calorimetry (DSC) thermograms and the results are presented in Fig. 1a and b, respectively.

Fig. 1 Endotherms of a unirradiated nanocomposites b nanocomposites irradiated at $100 \mathrm{kGy}$
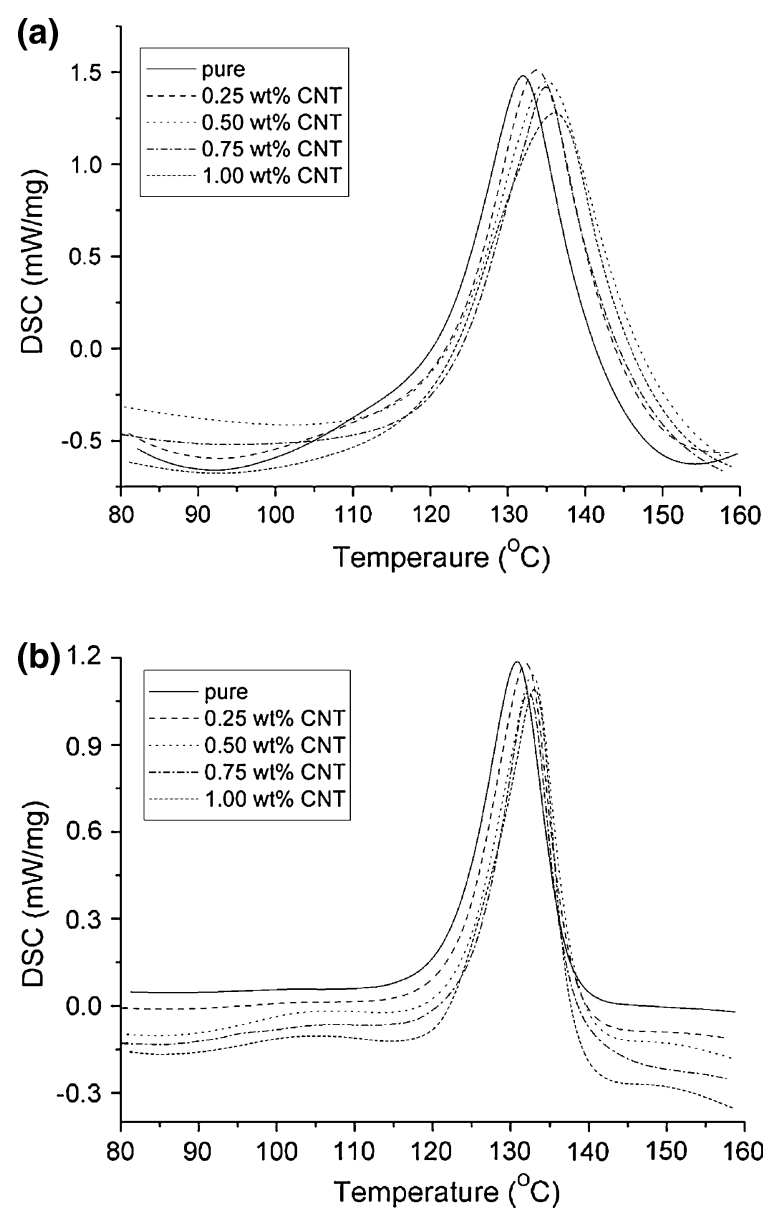
It is observed from Fig. 1a that the melting temperature of unirradiated nanocomposites was found to be slightly varied for different concentrations of MWCNTs. Upon irradiation of the nanocomposites, the melting peak still shifted to higher values, as observed in Fig. 1b. It is observed that the melting temperature of HDPE was raised by increasing the concentration of MWNCTs and $\gamma$-irradiation doses. Typical parameters such as melting temperature and degree of crystallinity, were calculated from the DSC plots.

Figure 2a shows the variation of melting point of nanocomposites before and after irradiation. It is observed that the melting point of pure polymer was found to be $131.3{ }^{\circ} \mathrm{C}$, which was increased to $133.8{ }^{\circ} \mathrm{C}$ by incorporation of $1.0 \mathrm{wt} \%$ MWCNTs corresponding to $1.8 \%$ increase. When the nanocomposites were exposed to gamma irradiation at $100 \mathrm{kGy}$, the melting temperature of $1 \mathrm{wt} \%$ MWCNTs was raised $136.7{ }^{\circ} \mathrm{C}$, which corresponds to a raise of $4 \%$ compared to unirradiated pure polymer. The increase of melting temperature of nanocomposites with irradiation dosage confirmed that the melting process of the test samples was delayed due to the formation of crosslinks produced during the irradiation process, Premnath et al. [19, 20]. Furthermore, an increase of irradiation dose led to higher degree of crosslinking, which resulted in long branched molecules with infinite mass [21] and thus it is expected to demand higher heat input during the melting process resulting an increase of melting temperature of the nanocomposites.

The crystallinity of the nanocomposites was obtained by normalizing the heat of fusion of nanocomposites with that of a $100 \%$ crystalline material, $289.4 \mathrm{~J} / \mathrm{g}$ in this case [22]. Figure $2 \mathrm{~b}$ shows the degree of crystallinity of test materials against irradiation dosage and MWCNTs concentration. The crystallinity of nanocomposites was found to be increased with concentration of MWCNTs and gamma irradiation. It was found to be increased from 37.4 to $51.8 \%$ for $1 \mathrm{wt} \%$ MWNCTs in HDPE, which was then raised to $55.8 \%$ at $100 \mathrm{kGy}$ irradiation dose. The enhancement of crystallinity was $38.5 \%$ for $1 \mathrm{wt} \%$ of HDPE/MWCNTs nanocomposites and $49 \%$ for the same sample irradiated at $100 \mathrm{kGy}$ dose. The increase of crystallinity of the test sample with irradiation dose was due to the fact that chain scission occurred in addition to crosslinking during the irradiation process and these two processes progressed to a higher degree with an increase of dosage level. It was reported by Bhateja et al. [22] that the broken chains formed by the chain scission process were rearranged into the existing crystals, thus an increase of the crystal perfection in an irradiated nanocomposite was occurred. According to Kanagaraj et al. [18], MWCNTs acted as sites for nucleation of crystallization and thus it enhanced the crystallinity of the nanocomposites.

\subsection{Thermogravimetric Analysis}

Thermal stability of nanocomposites before and after gamma irradiation was studied and it is shown in Fig. $3 a$ and $b$. 
Fig. 2 Irradiation effect on a melting temperature and b \% crystallinity of nanocomposites
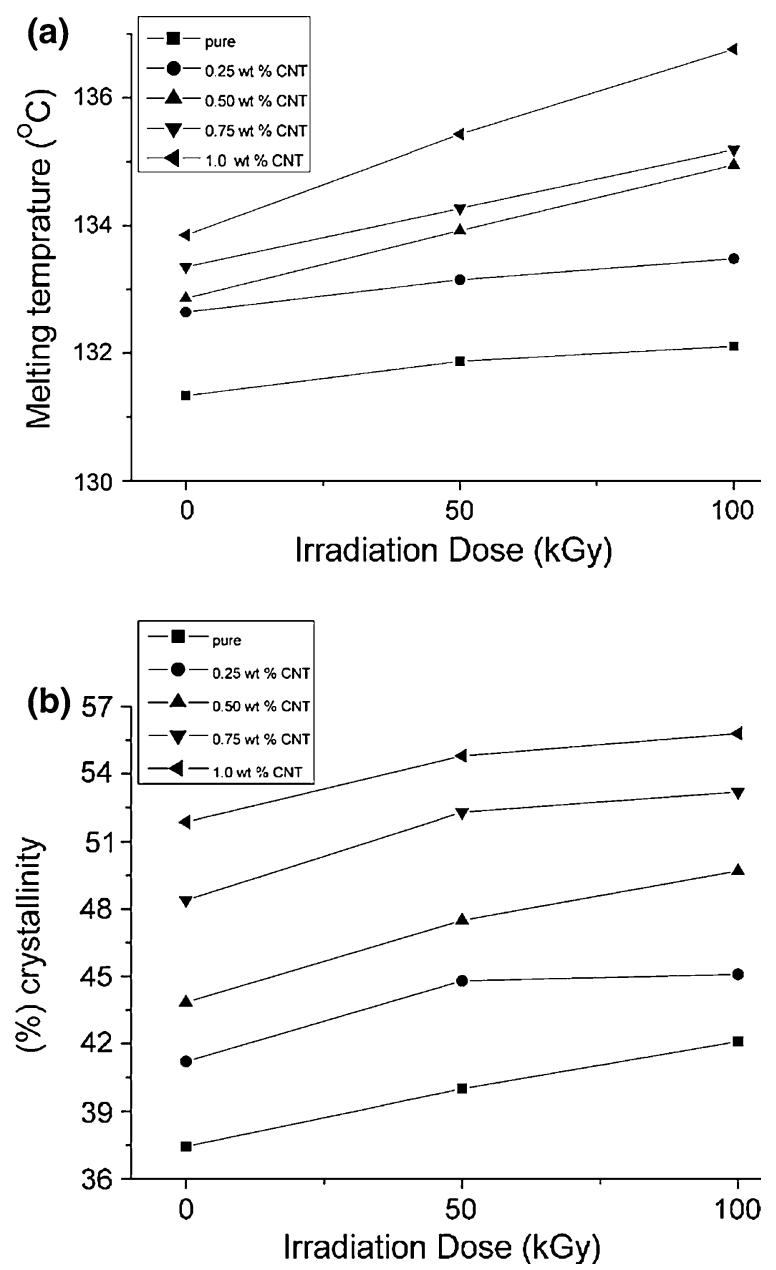

It is observed from Fig. 3 that all unirradiated and irradiated nanocomposites showed higher thermal stability than pure HDPE. It is observed from the results that all nanocomposites are having relatively good thermal stability up to $325{ }^{\circ} \mathrm{C}$ at $0 \mathrm{kGy}$ and it was increased to $400{ }^{\circ} \mathrm{C}$ at $100 \mathrm{kGy}$ irradiated dose. It is observed from Fig. 4 that the onset temperature of decomposition of unirradiated nanocomposite at $1 \mathrm{wt} \%$ of MWNCTs was increased from 457.2 to $467.7{ }^{\circ} \mathrm{C}$, while at $100 \mathrm{kGy}$ the corresponding value was raised from 465 to $473.1^{\circ} \mathrm{C}$. It is due to high thermal stability of MWCNTs that restrict the thermal degradation effect of polymer chains. 
Fig. 3 Thermal stability of a unirradiated nanocomposites and b irradiated nanocomposites at $100 \mathrm{kGy}$

Fig. 4 Effect of irradiation dose on onset temperature of degradation of nanocomposites
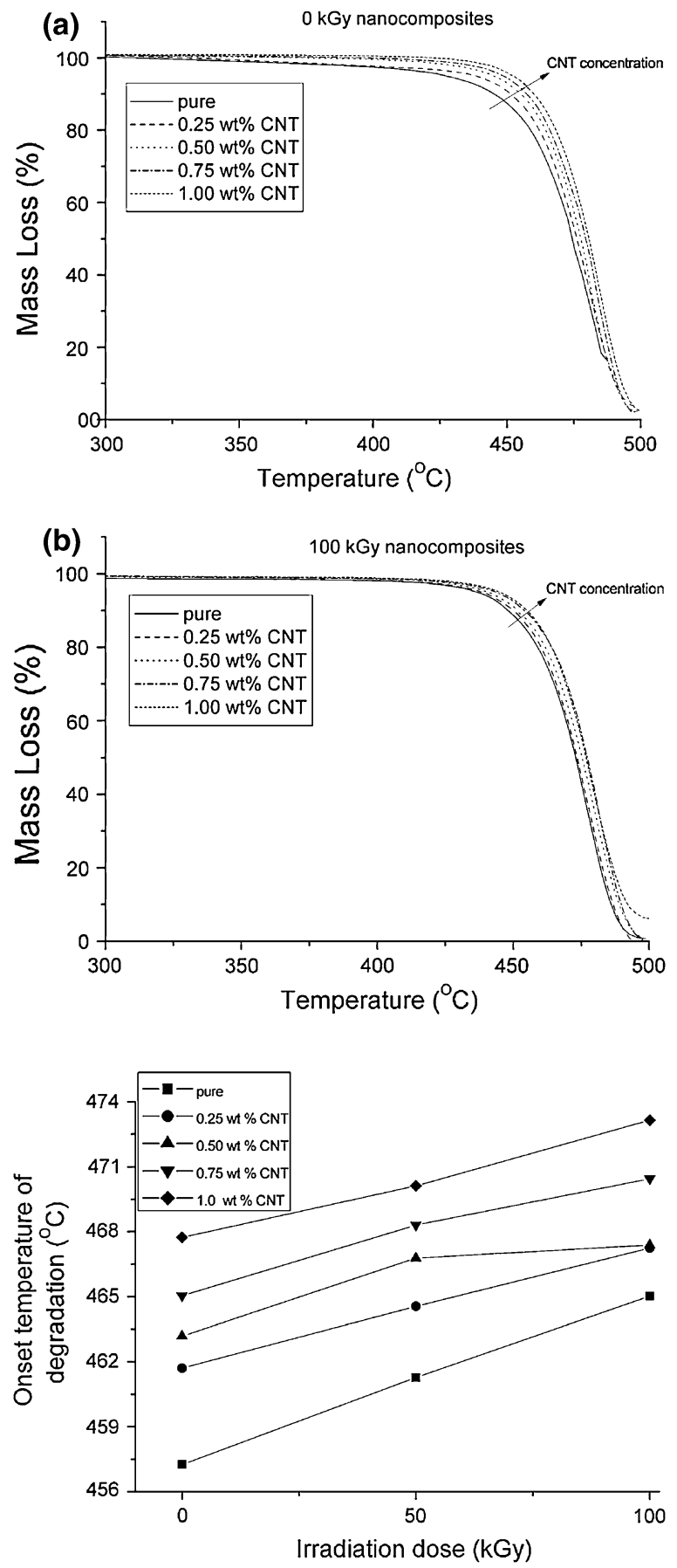


\subsection{Thermo-mechanical Analysis}

In order to investigate the dimensional stability of nanocomposites, thermal expansion of the unirradiated and irradiated samples was studied in the temperature range of $35-85^{\circ} \mathrm{C}$ and the results are shown in Fig. 5a and b.

It is observed from Fig. 5 that thermal expansion of both unirradiated and irradiated samples was decreased with an increase of MWCNTs and irradiation dosage but increased with temperature. Thermal expansion of pure HDPE was higher than that of nanocomposites at any concentration and irradiation dose. At $0 \mathrm{kGy}$, the linear strain of pure polymer was $5.87 \times 10^{-3} \mathrm{~m} / \mathrm{m}$ and it was reduced to $3.45 \times 10^{-3} \mathrm{~m} / \mathrm{m}$ at $1 \mathrm{wt} \%$ nanocomposite. When the nanocomposites were exposed to gamma irradiation at $100 \mathrm{kGy}$, the linear strain of $1.0 \mathrm{wt} \%$ nanocomposite was further reduced to $2.64 \times 10^{-3} \mathrm{~m} / \mathrm{m}$ whereas the same for pure HDPE was $3.90 \times 10^{-3} \mathrm{~m} / \mathrm{m}$.

Fig. 5 Linear strain of a unirradiated nanocomposites and b irradiated nanocomposites at $100 \mathrm{kGy}$
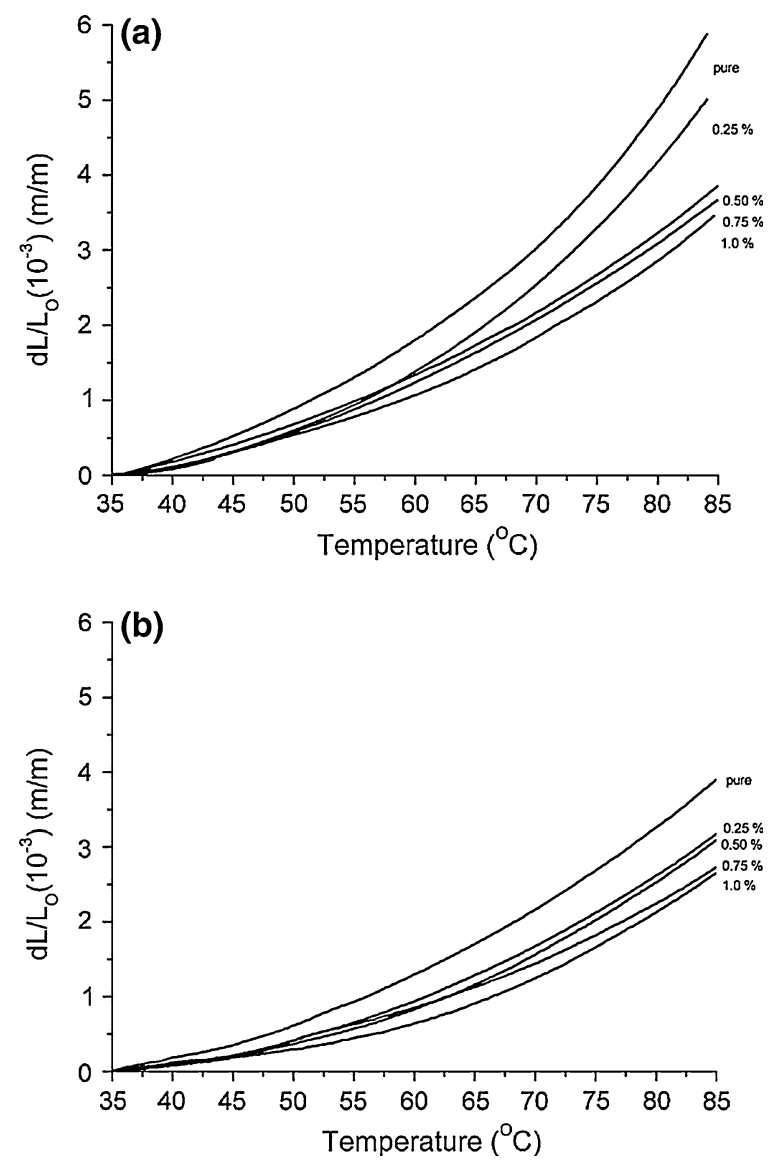
It is observed from Fig. 6 that thermal expansion of HDPE was decreased by 41.2 and $55 \%$ for $1 \mathrm{wt} \%$ of MWNCTs and $100 \mathrm{kGy}$ irradiation, respectively. In general, it is observed that the percentage decrease of linear strain of pure polymer is decreased by increasing the concentration of MWNCTs and the irradiation dosage level. The presence of MWCNTs and crosslinking induced by the irradiation resulted in long molecular chains with infinite mass restricting the mobility of polymer chains, which led to the reduction of linear thermal expansion of polymer and nanocomposites [23].

The coefficient of thermal expansion (CTE) of both unirradiated and irradiated nanocomposites was calculated in the temperature range of $40-80{ }^{\circ} \mathrm{C}$ at an interval of $10{ }^{\circ} \mathrm{C}$, where the reference temperature was considered as $35^{\circ} \mathrm{C}$. Figure $7 \mathrm{a}$ and $\mathrm{b}$ show the CTE of nanocomposites at 0 and $100 \mathrm{kGy}$ irradiation dose, respectively.

It is observed from Fig. 7a, b that (1) CTE of all test samples increased with temperature, (2) CTE of the sample was significantly restricted with an increase of the concentration of MWCNTs, (3) $\gamma$-irradiation also influenced to restrict CTE of test samples. It is observed that the CTE of unirradiated pure polymer at 40 and $80{ }^{\circ} \mathrm{C}$ was calculated to be 44.9 and $108.6 \mu \mathrm{m} / \mathrm{m}-\mathrm{K}$, respectively, whereas the same for $1 \mathrm{wt} \%$ nanocomposite, it was reduced by 62 and $41 \%$, respectively. Similarly at $100 \mathrm{kGy}$ irradiation dose, the CTE for the pure polymer at same temperatures was noted to be 37.6 and $72.6 \mu \mathrm{m} / \mathrm{m}-\mathrm{K}$, and it was reduced by 57 and $35 \%$, respectively for $1 \mathrm{wt} \%$ nanocomposites. The reduction of CTE of nanocomposites could be attributed to very low intrinsic thermal expansion of nanotubes, which is $26 \mathrm{~nm} / \mathrm{m}$ up to $800 \mathrm{~K} \mathrm{[24]} \mathrm{and} \mathrm{thus} \mathrm{it} \mathrm{is} \mathrm{expected} \mathrm{to} \mathrm{restrict} \mathrm{CTE} \mathrm{of}$ pure polymer. Moreover, MWCNTs have very high specific surface area and hence the interfacial area between MWCNTs and polymer matrix is of very high order resulting to the reduction of CTE of the composites.

Fig. 6 Effect of irradiation dose on percentage decrease of linear strain of nanocomposites

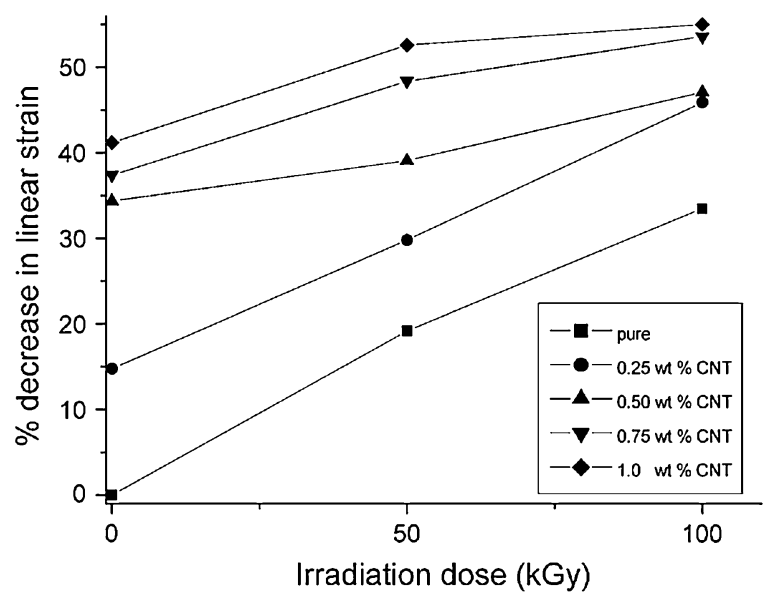


Fig. 7 Coefficient of thermal expansion of nanocomposites at a $0 \mathrm{kGy}$ and b $100 \mathrm{kGy}$ irradiation dose
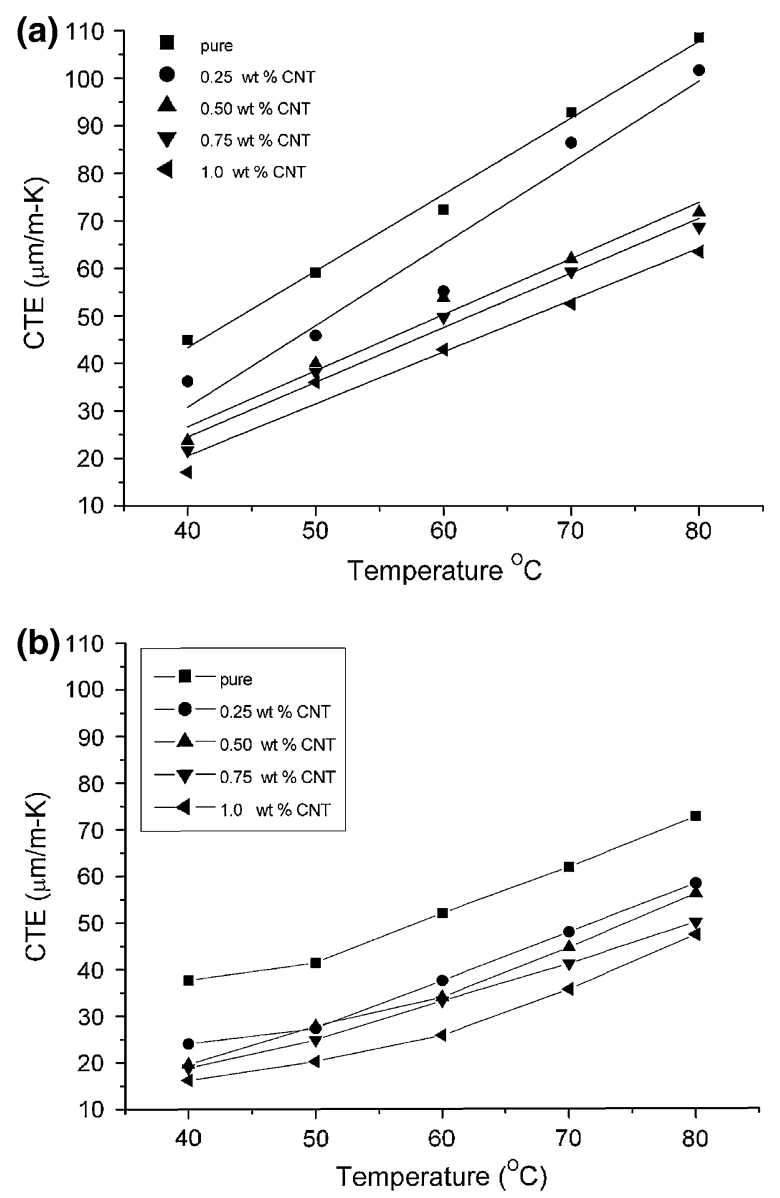

\section{Conclusions}

Thermal characterization of gamma irradiated high density polyethylene reinforced with multiwalled carbon nanotube nanocomposites was studied and the following conclusions are drawn for nanocomposites having $1 \mathrm{wt} \%$ MWCNTs and irradiated at $100 \mathrm{kGy}$.

- The melting temperature and crystallinity of HPDE was enhanced both by presence of MWCNTs and gamma irradiation as well. At $1 \mathrm{wt} \%$ MWCNTs in HDPE and $100 \mathrm{kGy}$ irradiation dose, the melting temperature and crystallinity were increased by $5.4{ }^{\circ} \mathrm{C}$ and $49 \%$ respectively.

- The onset temperature of degradation of HDPE was delayed by MWCNT reinforcement and irradiation. At $1 \mathrm{wt} \%$ MWCNTs and $100 \mathrm{kGy}$ irradiation dose, the degradation was delayed by about $75^{\circ} \mathrm{C}$. 
- Dimensional stability of HDPE greatly enhanced by the presence of MWCNTs. It was improved by $56 \%$ upon irradiating $1 \mathrm{wt} \%$ nanocomposite at $100 \mathrm{kGy}$.

Acknowledgments Authors gratefully acknowledge the Department of Science and Technology, India, for funding through a project IDP/MED/2009/04. Technical support given by M/s Microtrol sterilization Pvt. Ltd, Bangalore, Prof. J. A. O. Simoes, University of Aveiro, Portugal, staff from Central Institute Facility and Materials science laboratory at IITG is kindly acknowledged.

\section{References}

1. J.B. Park, R.S. Lakes, Biomaterials: An Introduction, 2nd edn. (Plenium press, New York, 1992)

2. S.-H. Yu, J.-T. Yeh, B.-C. Huang, K.-S. Huang, Preparation of HDPE/Carbon nanotube composite. Polym. Plast. Technol. Eng. 49, 15, 1534 (2010)

3. H. Fouad, R. Elleithy, High density polyethylene/graphite nano-composites for total hip joint replacements: Processing and in vitro characterization. J. Mech. Behav. Biomed. Mater. 4, $1376(2011)$

4. M. Wang, S. Deb, W. Bonfield, Chemically coupled hydroxyapatite-polyethylene composites: processing and characterization. Mater. Lett. 44, 119 (2000)

5. Z.H. Liu, K.W. Kwok, R.K.Y. Li, C.L. Choy, Effects of coupling agent and morphology on the impact strength of high density polyethylene/ $\mathrm{CaCO}_{3}$ composites. Polymer $\mathbf{4 3}, 2501(2002)$

6. R. Yang, J. Yu, Y. Liu, K. Wang, Effects of inorganic fillers on the natural photo-oxidation of high-density polyethylene. Polym. Degrad. Stab. 88, 333 (2005)

7. P.M. Ajayan, O. Stephan, C. Colliex, D. Trauth, Aligned carbon nanotube arrays formed by cutting a polymer resin-nanotube composite. Science 265, 212 (1994)

8. H. Fouad, R. Elleithy, S.M. Al-Zahrani, M.A. Ali, Characterization and processing of high density polyethylene/carbon nano-composites. Mater. Des. 32, 1974 (2011)

9. M. Trujillo, M.L. Arnal, A.J. Müller, E. Laredo, Bredeau, D. Bonduel, Ph. Dubois, Thermal and morphological characterization of nanocomposites prepared by in situ polymerization of high-density polyethylene on carbon nanotubes. Macromolecules 40, 6268 (2007)

10. K. Chrissafis, K.M. Paraskevopoulos, E. Pavlidou, D. Bikiaris, Thermal degradation mechanism of HDPE nanocomposites containing fumed silica nanoparticles. Thermochim. Acta 485, 65 (2009)

11. S. Sahebian, S.M. Zebarjad, J.V. Khaki, S.A. Sajjadi, The effect of nano-sized calcium carbonate on thermodynamic parameters of HDPE. J. Mater. Process. Technol. 209, 1310 (2009)

12. S.L. Kodjie, L. Li, B. Li, W. Cai, C.Y. Li, M. Keating, Morphology and crystallization behavior of HDPE/CNT nanocomposite. J. Macromol. Sci., Part B 45, 2, 231 (2006)

13. M. Dole, Cross-linking and crystallinity in irradiated polyethylene. Polym. Plast. Technol. Eng. 13, 41 (1979)

14. S.K. Bhateja, E.H. Andrews, R.J. Young, Radiation-induced crystallinity changes in linear polyethylene. J. Polym. Sci. Part B 21, 523 (1983)

15. C.C. Puig, C. Albano, E. Laredo, E. Quero, A. Karam, Thermal characterization of the HDPE/LDPE blend (10/90) irradiated using $\gamma$-rays. Nucl. Instrum. Methods Phys. Res, Sect. B 268, 1466 (2010) 
16. L. Cataño, C. Albano, A. Karam, N. Domínguez, Y. Sánchez, J. González, Effect of gamma irradiation on mechanical, thermal and rheological behavior of HDPE filled with seaweed residues. Nucl. Instrum. Methods Phys. Res., Sect. B 236, 348 (2005)

17. A. Carmen, K. Arquímedes, P. Rosestela, G. Gema, D. Nohemy, G. Jeanette, S. Yanixia, HDPE/HA composites obtained in solution: Effect of gamma radiation. Nucl. Instrum. Methods Phys. Res., Sect. B 247, 331 (2006)

18. S. Kanagaraj, F.R. Varanda, T.V. Zhil'tsova, M.S.A. Oliveira, J.A.O. Simões, Mechanical properties of high density polyethylene/carbon nanotube composites. Compos. Sci. Technol. 67, 3071 (2007)

19. V. Premnath, W.H. Harris, M. Jasty, E.W. Merrill, Gamma sterilization of UHMWPE articular implants: an analysis of the oxidation problem. Biomaterials 17, 1741 (1996)

20. V. Premnath, A. Bellare, E.W. Merrill, M. Jasty, W.H. Harris, Molecular rearrangements in ultra high molecular weight polyethylene after irradiation and long-term storage in air. Polymer 40, 2215 (1999)

21. P.C.P. Watts, P.K. Fearon, W.K. Hsu, N.C. Billingham, H.W. Kroto, D.R.M. Walton, Carbon nanotubes as polymer antioxidants. J. Mater. Chem. 13, 491 (2003)

22. S.K. Bhateja, R.W. Duerst, J.A. Martens, E.H. Andrews, Radiation-induced enhancement of crystallinity in polymers. J. Macromol. Sci. RMC 4, 581 (1995)

23. C.F. Deng, Y.X. Ma, P.Zhang, X.X. Zhang, D.Z. Wang (2008), Thermal expansion behaviors of aluminum composite reinforced with carbon nanotubes. Mater. Lett. 62, 2301 (2008)

24. M.N. Prakash, Master's thesis, Department of mechanical engineering, College of engineering, The Florida State University (2005) 